\title{
Flow and heat transfer analysis of Eyring-Powell fluid over stratified sheet with mixed convection
}

\author{
Muhammad Bilal ${ }^{*}$ (D) and Samia Ashbar
}

*Correspondence:

m.bilal@math.uol.edu.pk

Department of Mathematics and

Statistics, The University of Lahore,

Gujrat Campus, Gujrat, Pakistan

\begin{abstract}
This article presents the study of heat transfer under the influence of mixed convective flow of Eyring-Powell fluid over a stratified stretching sheet. The impact of heat generation/absorption is also discussed. The fluid is considered to be a viscous, incompressible, two dimensional, and laminar. Transformation, based on the similarity variables, is used for the alteration of modeled governing partial differential equations (PDEs) into ordinary differential equations (ODEs). The shooting approach is introduced to accomplish the mathematical solution of governing equations. Runge-Kutta method of order four is used for the integration purpose and Newton's method helps to refine initial guesses. All the programming is done on MATLAB. The effects of emerging parameters on temperature and velocity profiles are discussed through graphs. The related physical properties of flow, i.e., the skin friction coefficient and Nusselt number are described graphically for various parameters. Numerical values for the Nusselt number and skin friction coefficient are tabulated for the various parameters. It is noted that increment in thermal stratification parameter yields fall in both velocity and temperature of fluid and a reverse relation is observed for the heat generation parameter.
\end{abstract}

Keywords: Heat transfer, Thermal stratification, Mixed convection, Eyring-Powell fluid, Heat generation

\section{Introduction}

Heat transfer is a mechanism through which internal energy is transferred from one material to another. It is one of the key point for the researchers, physicists, engineers, and mathematicians. It is extremely important to study the impact of heat transfer in various materials and boundary layer flows over stretching sheet due to their considerable applications in various biological phenomena, engineering processes, and industrial units like paper production, metal extrusion, fermentation, and bubble absorption [1-13]. The basic concern of heat transfer study is to prevent the heat loss in important industrial processes. The heat loss has one of the disadvantage that it increases the cost of product due to extra consumption of heat as well as it may cause the malfunctioning of the products. Heat transfer occur in three ways known as conduction, convection, and radiation. Heat

(c) The Author(s). 2020 Open Access This article is licensed under a Creative Commons Attribution 4.0 International License, which permits use, sharing, adaptation, distribution and reproduction in any medium or format, as long as you give appropriate credit to the original author(s) and the source, provide a link to the Creative Commons licence, and indicate if changes were made. The images or other third party material in this article are included in the article's Creative Commons licence, unless indicated otherwise in a credit line to the material. If material is not included in the article's Creative Commons licence and your intended use is not permitted by statutory regulation or exceeds the permitted use, you will need to obtain permission directly from the copyright holder. To view a copy of this licence, visit http://creativecommons.org/licenses/by/4.0/. 
transfer through physical contact, through motion of fluid, or through radiation is called conduction, convection, and radiation respectively. In general terms when we talk about convection, the heat transfer occurs between some sorts of fluid and fixed or moving surface. The process of convection is divided into three sub categories, free convection or natural convection, forced convection, and mixed convection. The basic principle dealing with the natural or free convection is through continuous transfer of the heat flow between two surfaces or materials when there is considerable force of buoyancy. When we talk about forced convection, there is some sort of external force that causes to transfer the heat between the two materials. Chen [14] provided an analysis of mixed convection in boundary layers flow on a vertical and constantly stretching sheet. He used finite difference method to solve the problem. Ali [15] researched numerically the impact of temperature-dependent viscosity on the laminar mixed convection flow over a continually moving vertical surface. He found the critical values of mixed convection for which variable viscosity assists or oppose the flow. Hayat et al. [16] provided an analysis for the two-dimensional mixed convection boundary layer flow on MHD stagnation point through a porous medium bounded by a vertical stretching plate, taking into account the radiation effect. Ali and Yousef [17] analyzed the boundary layer flow due to buoyancy forces through a uniformly moving vertical surface with suction or injection. The plate when placed vertically affects the heat flow and the buoyancy factor. Khan et al. [18] investigated the important aspects of magnetic nanofluids and stratification process under the linear convection. Shooting method is applied for the non-linear stretching sheet to analyze the impact of viscosity effects and understand the different behaviors of Willamson nanofluid. Hayat et al. [19] examined the MHD effect with Joule heating for heat and mass transfer through the double stratified sheet. The various physio-chemical parameters of heat flow are analyzed both numerically and graphically. The results shows the subsequent reduction of mean absorption coefficient with increase in temperature profiles. Heat and fluid flow passing over a rotating disk was considered by Hayat et al. [20]. The magnetohydrodynamics flow of nanofluid using the double stratification impact is analyzed analytically. The analytical solutions were calculated after the use of boundary layer approximation. The results depict that the Prandtl number has direct relation with heat flow and indirect with the temperature of the fluid.

Fluid flow analysis along stretching/shrinking sheet is a major concern for researchers. The maximum composition of our cellular mass is consisting of fluids, air, and water, and there are subsequent amount of essential body fluids in correct proportion that aids to lead a healthy life. The fluid flow over a stretched surface has many applications in industrial processes and engineering, liquid films in condensation process, paper production, drawing of plastic wires and films, crystal glowing, glass blowing, food industries, coatings, drug delivery system, paints, ceramics, manufacturing of rubber sheets, etc. Sakiadis [21, 22] was the first to examine the boundary layer flow on a continuous flat and cylindrical surfaces moving at a coherent velocity. Dandapat and Gupta [23] analyzed the heat transfer flow in the viscoelastic fluid along the stretching sheet. The boundary layer flow was analyzed in depth over a continuous solid surface and contrasted with the moving surface of finite length. Erickson et al. [24] considered the boundary layer flow with suction and injection and numerically resolved the energy and the diffusion equation. Flow produced by stretching sheet is discussed by Crane [25]. Anderson et al. [26] examined the power-law fluid flow under the effect of magnetic forces, over a 
linearly stretched surface. An Oldyroyd-B fluid flow with the influence of heat generation/absorption is depicted by Hayat et al. [27]. Fluid flow over curved stretching surface using curvi-linear coordinate was first investigated by Sajid et al. [28].

Scientists nowadays are trying to investigate the effects of shear stress and fluid flow of non-Newtonian fluids due to their industrial need. The nature of the non-Newtonian fluids is diverse and cannot be explained by a single reference equation. The non-Newtonian fluids exhibit a non-linear correlation between stress and strain. The preference is given to Eyring-Powell fluid over the other non-Newtonian fluids due to the fact that it is based on kinetic molecular model of liquids not on the empirical relation. The key role of various fluids in industries draws the attention of investigators to look and find their usage and hurdles caused by various heat flow phenomenon. Ibrahim et al. [29] investigated the magnetohydrodynamics (MHD) boundary layer flow of Eyring-Powell nanofluid by using the Cattaneo-Christov heat flux model. The purpose of this study was to discuss the strong correlation between the influx of heat transfer, characterization for the conservation of mass, energy, and momentum. Eldabe et al. [30] tried to focus on magnetohydrodynamics effect on non-Newtonian, unsteady and incompressible fluid when subjected to the extreme stress in combination with outlying electric field. The mathematical model of Eyring-Powell fluid was solved by applying the computational tools on non-linear partial differential equations. Both the first-order and second-order approximation were being calculated by the finite difference technique. Malik et al. [31] tried to investigate the mixed convection flow over the stretching plate for MHD Eyring-Powell fluid and numerically solved the problem by applying shooting method. The results indicate significant decrease in heat and mass transfer by enhancing Eyring-Powell material parameter. A study is being carried by Ogunseye et al. [32] that focuses the thermal properties and characteristics of Eyring-Powell nanofluid for minimum entropy loss. A recent study of Prand et al. [33] discusses the boundary layer flow of Eyring-Powell fluid with thermal and physio-chemical aspects of heat and fluid flow. Saleh et al. [34] investigated comprehensively the transferal of heat and the uniform, steady boundary layer flow of Eyring-Powell fluid by Newtonian heating model. They have implemented the finite-difference method to solve the nonlinear differential equations.

After carefully reviewing the above cited research, it is feel that the Eyring-Powell fluid model with mixed convection boundary layer flow over a stratified stretching sheet with heat generation/absorption is still missing in the literature. The model includes an energy equation to analyze the temperature flow over the stratified stretching sheet. By using the boundary layer approximation and implementing appropriate similarity transformations, the governing partial differential equations together with the boundary conditions are changed to dimensionless form. Numerical scheme based primarily on shooting technique is implemented for ODEs system. Graphs and tables are used to discuss the impacts of distinct physical parameters. Numerical outcomes for the Nusselt number and skin friction are also calculated. At the end of this article, we will be able to answer the folliwng questions: What is the impact of Eyring-Powell fluid parameter on the velocity profile? Does the mixed convection parameter have any effect on the velocity of the fluid? How does the stratified sheet help to boost the temperature of the fluid? Is the impact of heat generation and heat absorption the same? 


\section{Mathematical formulation}

A two-dimensional steady mixed convection flow of an incompressible Eyring-Powell fluid through stratified stretching sheet has been considered as given in Fig. 1. Sheet is stretching at constant speed $U_{w}=a x$ in vertical direction along the $x-$ axis. $T_{w}$ and $T_{\infty}$ are respectively the fluid temperature at wall and far away from the wall. The free stream velocity of the fluid is 0 . Further, the effect of heat generation absorption is reviewed in the energy equation. In the problem, we have ignored the suction/injection and viscous dissipation effects.

The boundary layer approximation reduces the equation of continuity and the equation of momentum into the following form [35]:

$$
\begin{aligned}
& \frac{\partial u}{\partial x}+\frac{\partial v}{\partial y}=0, \\
& u \frac{\partial u}{\partial x}+v \frac{\partial u}{\partial y}=\left(v+\frac{1}{\rho \beta C}\right) \frac{\partial^{2} u}{\partial y^{2}}-\frac{1}{2 \rho \beta C^{3}}\left(\frac{\partial u}{\partial y}\right)^{2} \frac{\partial^{2} u}{\partial y^{2}}+g \beta\left(T-T_{\infty}\right),
\end{aligned}
$$

where $\beta$ and $C$ are the dimensional Eyring-Powell fluid material parameters, $\mu$ represents the kinematic viscosity of fluid, and $g$ denotes the gravitational acceleration. Under boundary layer approximation, the energy equations takes the form:

$$
u \frac{\partial T}{\partial x}+v \frac{\partial T}{\partial y}=\frac{k}{\rho C_{p}} \frac{\partial^{2} T}{\partial y^{2}}+\frac{Q}{\rho C_{p}}\left(T-T_{\infty}\right),
$$

where $k$ denotes thermal conductivity, $C_{p}$ is the specific heat at constant pressure, and $Q$ is the heat generation/absorption coefficient. The boundary conditions for the present flow problem is given by

$$
\begin{aligned}
& u=U_{w}=a x, \quad v=0, \quad T=T_{w}=T_{0}+b_{1} x \quad \text { at } \quad y=0, \\
& u \rightarrow 0 \Rightarrow \quad T \rightarrow T_{\infty}=T_{0}+b_{2} x, \quad y \rightarrow \infty, \quad \text { as } y \rightarrow \infty,
\end{aligned}
$$

where $u$ and $v$ represent the horizontal and vertical components of fluid velocity. Also, $T_{0}$ is used to denote the stretching sheet reference temperature and $b_{1}$ and $b_{2}$ are positive

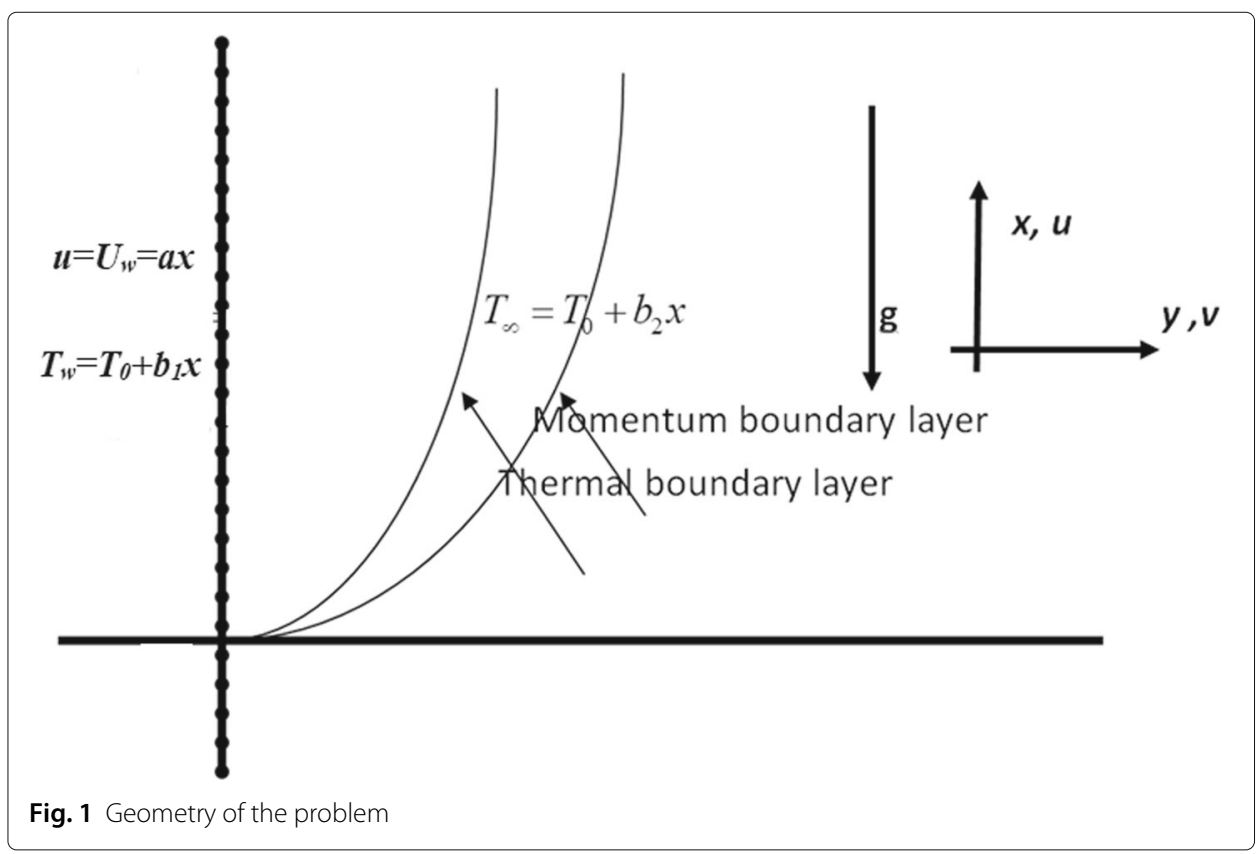


dimensional constants. The simultaneous PDEs with the corresponding boundary conditions are reduced to ODEs using similarity transformation. In this case, the equation of continuity is identically satisfied while the momentum and energy equations are reduced to non-dimensional ODEs. The following stream function is defined

$$
u=\frac{\partial \varphi}{\partial y}, v=-\frac{\partial \varphi}{\partial x}
$$

now using the recommended similarity transformation as

$$
\begin{aligned}
& \varphi=\sqrt{a \nu} x f(\eta), \eta=\sqrt{\frac{a}{v}} y, \\
& \theta(\eta)=\frac{T-T_{\infty}}{T_{w}-T_{0}} \Rightarrow T=\left(T_{w}-T_{0}\right) \theta(\eta)+T_{\infty},
\end{aligned}
$$

where $\varphi$ is stream function, $f(\eta)$ is dimensionless stream function, and $\eta$ presents similarity variable, also

$$
T=b_{1} x \theta(\eta) \text { and } T_{\infty}=T_{0}+b_{2} x,
$$

So, the final dimensionless form of the present problem's mathematical model is

$$
\begin{aligned}
& (1+\epsilon) f^{\prime \prime \prime}-\epsilon \sigma f^{\prime \prime 2} f^{\prime \prime \prime}-f^{\prime 2}+f f^{\prime \prime}+\lambda \theta=0, \\
& \theta^{\prime \prime}+\operatorname{Pr} \theta^{\prime} f-\operatorname{Pr} \theta f^{\prime}-\operatorname{Pr} e_{1} f^{\prime}+\operatorname{Pr} \gamma \theta=0,
\end{aligned}
$$

with boundary conditions

$$
\left.\begin{array}{l}
f(0)=0, f^{\prime}(0)=1, \quad \theta(0)=1-e_{1}, \text { at } y=0, \\
f^{\prime}(\eta)=0, \quad \theta(\infty)=0, \text { as } \eta \longrightarrow \infty,
\end{array}\right\}
$$

different parameters used in the above equations have the following formulations:

$$
\epsilon=\frac{1}{\rho \nu \beta C}, \quad \sigma=\frac{a U w^{2}}{2 C^{2} v}, \quad \lambda=\frac{G r_{c}}{R e_{x}^{2}}=\frac{g \beta b_{1}}{a^{2}}, \quad \operatorname{Pr}=\frac{\mu C_{p}}{K}, \quad e_{1}=\frac{b_{2}}{b_{1}} \quad \gamma=\frac{Q}{\rho C_{p} a},
$$

skin friction coefficient and Nusselt number is given as

$$
C_{f x}=\frac{\tau_{w}}{\rho U_{w}^{2}}, N u_{x}=\frac{x q_{w}}{k\left(T_{w}-T_{\infty}\right)},
$$

$\tau_{w}$ is shear stress and $q_{w}=-k(\partial T / \partial y)_{y=0}$ is heat flux at the surface. The dimensionless form of skin friction coefficient and Nusselt number is

$$
\sqrt{\operatorname{Re}_{x}} C_{f}=(1+\epsilon) f^{\prime \prime}(0)-\frac{1}{3} \epsilon \sigma f^{\prime \prime^{3}}(0), N u_{x} / \operatorname{Re}_{x}^{1 / 2}=-\theta^{\prime}(0),
$$

where $R e_{x}$ represents local Reynolds number and is defined as

$$
R e_{x}=\frac{x U_{w}}{v}=\frac{a x^{2}}{v}
$$

\section{Solution methodology}

The governing problem is solved numerically by shooting method which is a very well known numerical technique [36-40]. For the transition of equations, first rewrite them again in the following form 


$$
\begin{aligned}
f^{\prime \prime \prime} & =\frac{f^{\prime^{2}}-f f^{\prime \prime}-\lambda \theta}{1+\epsilon-\epsilon \sigma f^{\prime \prime 2}} \\
\theta^{\prime \prime} & =\operatorname{Pr} f^{\prime} \theta-\operatorname{Prf} \theta^{\prime}+e_{1} f^{\prime}-\operatorname{Pr} \gamma \theta
\end{aligned}
$$

The problems with the boundary value can not be analytically solved readily because these ODEs are nonlinear and coupled. The technique of shooting was therefore regarded for the sake of numerical solutions. The fourth-order Runge Kutta and Newton's method are the main features in the shooting method for solving the nonlinear differential equations. Now, let us use the following notations to convert them into the first order ODEs.

$$
f=l_{1}, f^{\prime}=l_{2}, f^{\prime \prime}=l_{3,}, \theta=l_{4}, \theta^{\prime}=l_{5},
$$

the system obtained as:

$$
\left.\begin{array}{r}
l_{1}^{\prime}=l_{2}, \\
l_{2}^{\prime}=l_{3}, \\
l_{3}^{\prime}=\frac{l_{2}^{2}-l_{1} l_{3}-\lambda l_{4}}{1+\epsilon-\epsilon \sigma l_{3}^{2}} \\
l_{4}^{\prime}=l_{5}, \\
l_{5}^{\prime}=\operatorname{Pr} l_{2} l_{4}-\operatorname{Pr} l_{1} l_{5}+e_{1} l_{2}-\operatorname{Pr} \gamma l_{4},
\end{array}\right\}
$$

the initial conditions take the following form:

$$
\left.\begin{array}{l}
l_{1}(0)=0, l_{2}(0)=1, l_{3}(\eta)=c, \\
l_{4}(0)=1-e_{1}, l_{5}(0)=d,
\end{array}\right\}
$$

For the sake of numerical solution of the above system of equations, take the bounded domain $\left[0, \eta_{\infty}\right] . \eta_{\infty}$ is finite real number. Here, $c$ and $d$ are supposed initial conditions. Selection criteria of missing initial equations is

$$
l_{2}\left(\eta_{\infty}, c, d\right)-1=0 \quad l_{4}\left(\eta_{\infty}, c, d\right)=0
$$

initially $c=c_{0}, d=d_{0}$ is chosen as the missing condition. To refine these initial conditions, the Newton's method is utilized, which has the following iterative scheme

$$
\left(\begin{array}{c}
c_{n+1} \\
d_{n+1}
\end{array}\right)=\left(\begin{array}{l}
c_{n} \\
d_{n}
\end{array}\right)-\left(\begin{array}{cc}
\frac{\partial l_{2}}{\partial c} & \frac{\partial l_{2}}{\partial d} \\
\frac{\partial l_{4}}{\partial c} & \frac{\partial l_{4}}{\partial d}
\end{array}\right)^{-1}\left(\begin{array}{l}
l_{2} \\
l_{4}
\end{array}\right) .
$$

Initial value problem is solved by Rung-Kutta method of order four with $c_{0}$ and $d_{0}$ as the supposed initial conditions. Iterative process kept on working until the stopping criteria is obtained. The stopping criteria is given by

$$
\max \left\{\left|l_{2}-1\right|,\left|l_{4}\right|\right\}<\varepsilon,
$$

where $\varepsilon$ is a positive number and is fixed as $\varepsilon=10^{-6}$.

\section{Result and discussion}

In this section, the results are given in tabular and graphical form. Figure 2 shows the effect of $\epsilon$ (material parameter) on dimensionless velocity of the fluid. The parameter $\epsilon$ is inversely proportional to the non-Newtonian fluid's dynamic viscosity. Increase in $\epsilon$ will result in lower the flow resistance. This decrement in flow resistant will increase the velocity of the fluid. Figure 3 shows the effect of $\epsilon$ on temperature of the fluid. As 


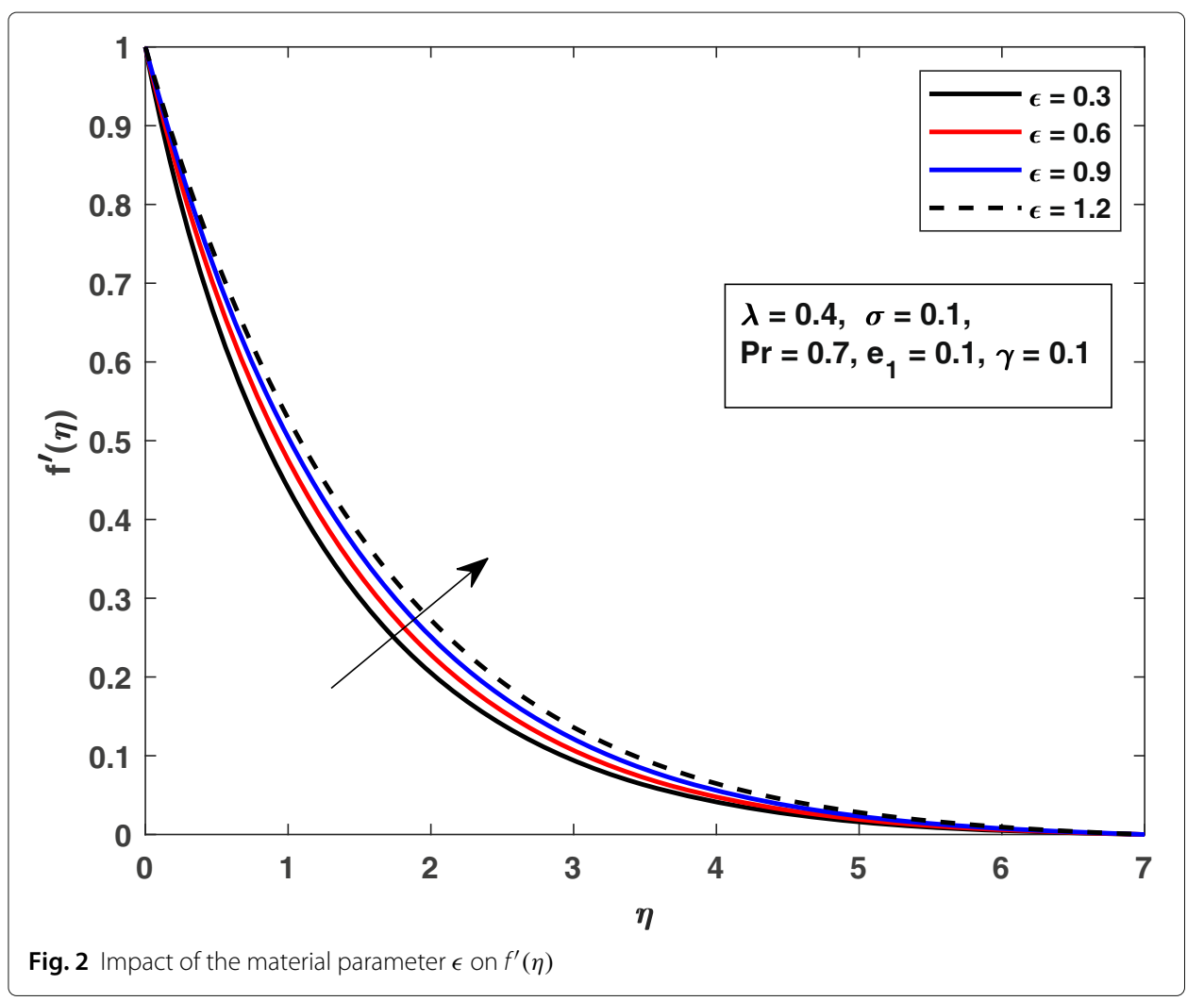

stated above, increase in $\epsilon$ decreases the viscosity of the fluid that contributes for the temperature reduction.

Figure 4 shows the impact of material parameter $\sigma$ on fluid velocity. We see from the graph that the velocity of fluid increases with an increase in $\sigma$. As $\sigma$ is directly related with the velocity of the sheet, and due to higher stretching speed, the velocity of the fluid will also enhances. Figure 5 shows the impact of $\sigma$ on temperature of the fluid. It is evident from the graph that the temperature of fluid decreases with an increase in $\sigma$. Figure 6 is drawn to see the influence of mixed convection parameter $\lambda$ on velocity profile. Graph depicts that enhancing $\lambda$ brings growth in fluid velocity. The reason behind this increment is the thermal buoyancy force. Due to higher buoyancy force, the momentum boundary layer thickness gets enlarged. Figure 7 shows the effect of mixed convection parameter $\lambda$ on temperature of the fluid. It is witnessed from the graph that boosting value of $\lambda$ causes a reduction in thermal buoyancy force which reduces the temperature of fluid. Figure 8 shows the influence of Prandtl number on velocity profile $f^{\prime}(\eta)$. $P r$ has direct relationship with viscosity of the fluid. Increase in $\operatorname{Pr}$ makes the fluid more dense, which causes a decrease in the velocity profile. Figure 9 gives the Prandtl number $P r$ effect on temperature profile. This dimensionless number is reversely associated with thermal conductivity $k$ and implies that the fluids with greater Prandtl number $P r$ holds weak energy diffusion. So, upgrading in Prandtl number $P r$ creates a strong reduction in temperature of the fluid which results in thinner thermal boundary layer. The impact of thermal stratification parameter $e_{1}$ is shown in Fig. 10. It is witnessed through the graph that magnifier thermal stratification declines the motion of the fluid. This effect is noted because of the reduction of the convective potential between sheet surface and ambient temperature. 


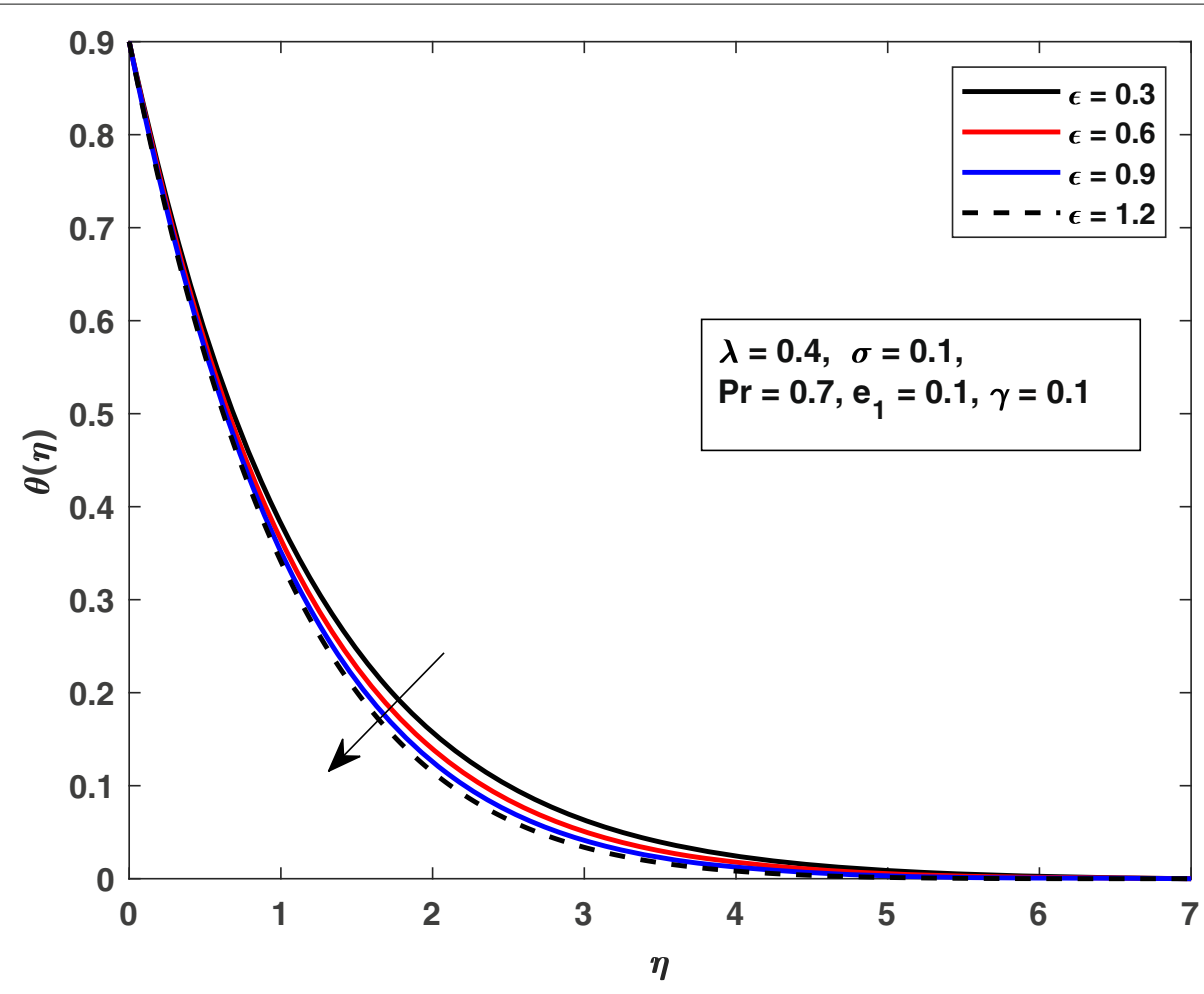

Fig. 3 Impact of the material parameter $\epsilon$ on $\theta(\eta)$

The temperature $\theta(\eta)$ of the moving fluid decreases for the higher stratification parameter. The temperature difference between the ambient fluid and the fluid on the surface declines with respect to $e_{1}$ which resultantly reduces the temperature as shown in Fig. 11 . Impact of $\gamma$ is displayed through Fig. 12. Increasing heat generation parameter $\gamma$ gives rise to the velocity of fluid over stretching sheet. The temperature of fluid increases with increasing the heat generation parameter $\gamma$ as shown in Fig. 13.

Table 1 shows the impact of material parameters $\sigma$ and $\epsilon$, Prandtl number $P r$, mixed convection parameter $\lambda$, thermal stratification parameter $e_{1}$, and chemical reaction parameter $\gamma$ on skin friction coefficient and Nusselt number. Material parameters $\epsilon$ and $\sigma$, mixed convection parameter $\lambda$, and heat generation parameter $\gamma$ have a direct relation with skin friction. Increase in these parameters shows an increment in skin friction while increase in Prandtl number and thermal stratification parameter causes a reduction in the skin friction coefficient. Heat generation parameter $\gamma$ and fluid material parameter $\sigma$ shows a direct relation with Nusselt number $-\theta^{\prime}(0)$. Increasing these parameters causes a rise in the value of Nusselt number whereas increasing $\epsilon$, mixed convection parameter $\lambda$, Prandtl number $P r$, and thermal stratification parameter $e_{1}$ shows a decrease in the value of Nusselt number.

\section{Summary}

In this article, we have explored the mixed convection boundary layer flow of EyringPowell fluid through the stratified stretching sheet. The fluid's characteristics such as viscosity and thermal conductivity are taken independent of temperature. The dimensionless velocity and dimensionless temperature are investigated and displayed in the 


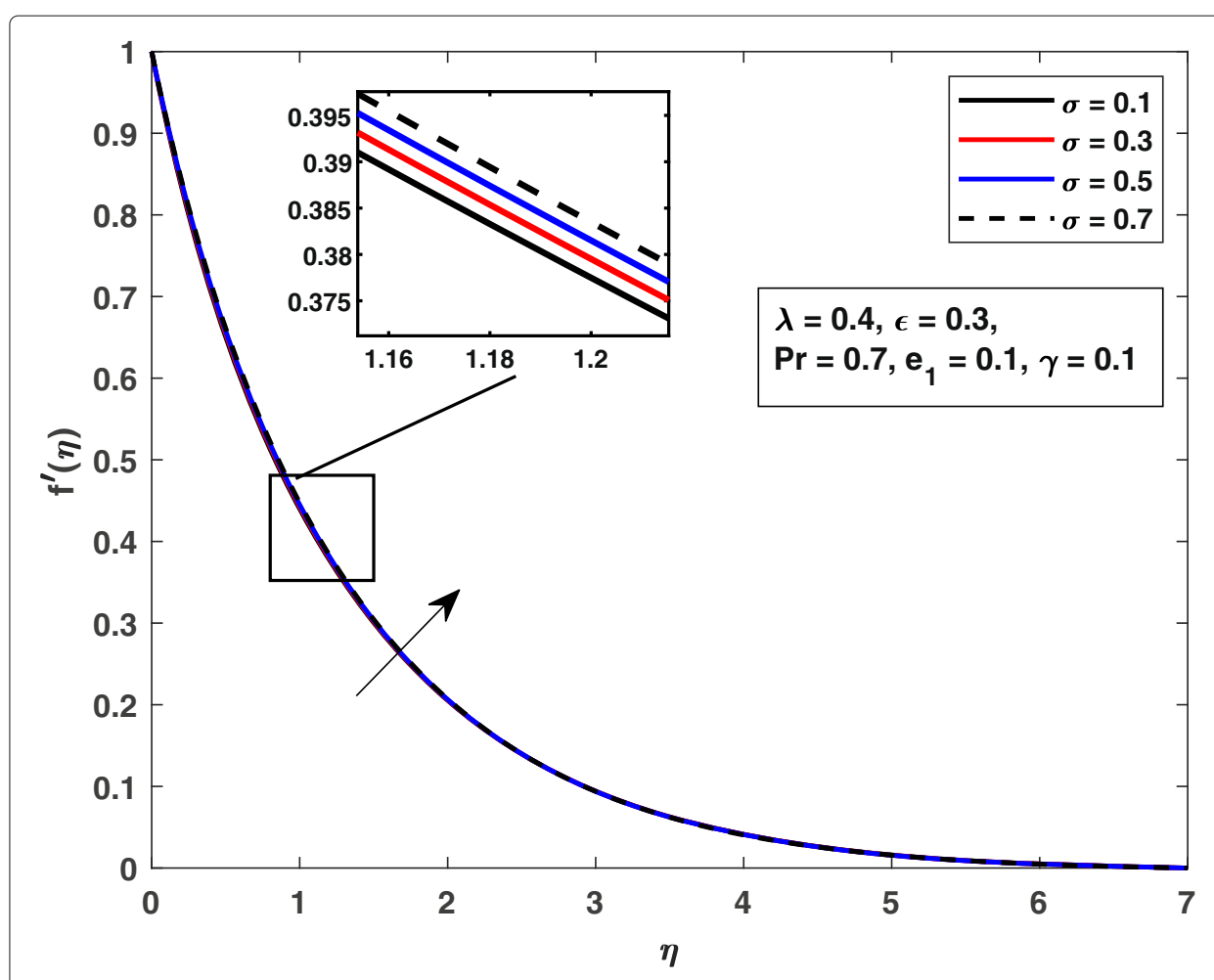

Fig. 4 Impact of the fluid parameter $\sigma$ on $f^{\prime}(\eta)$

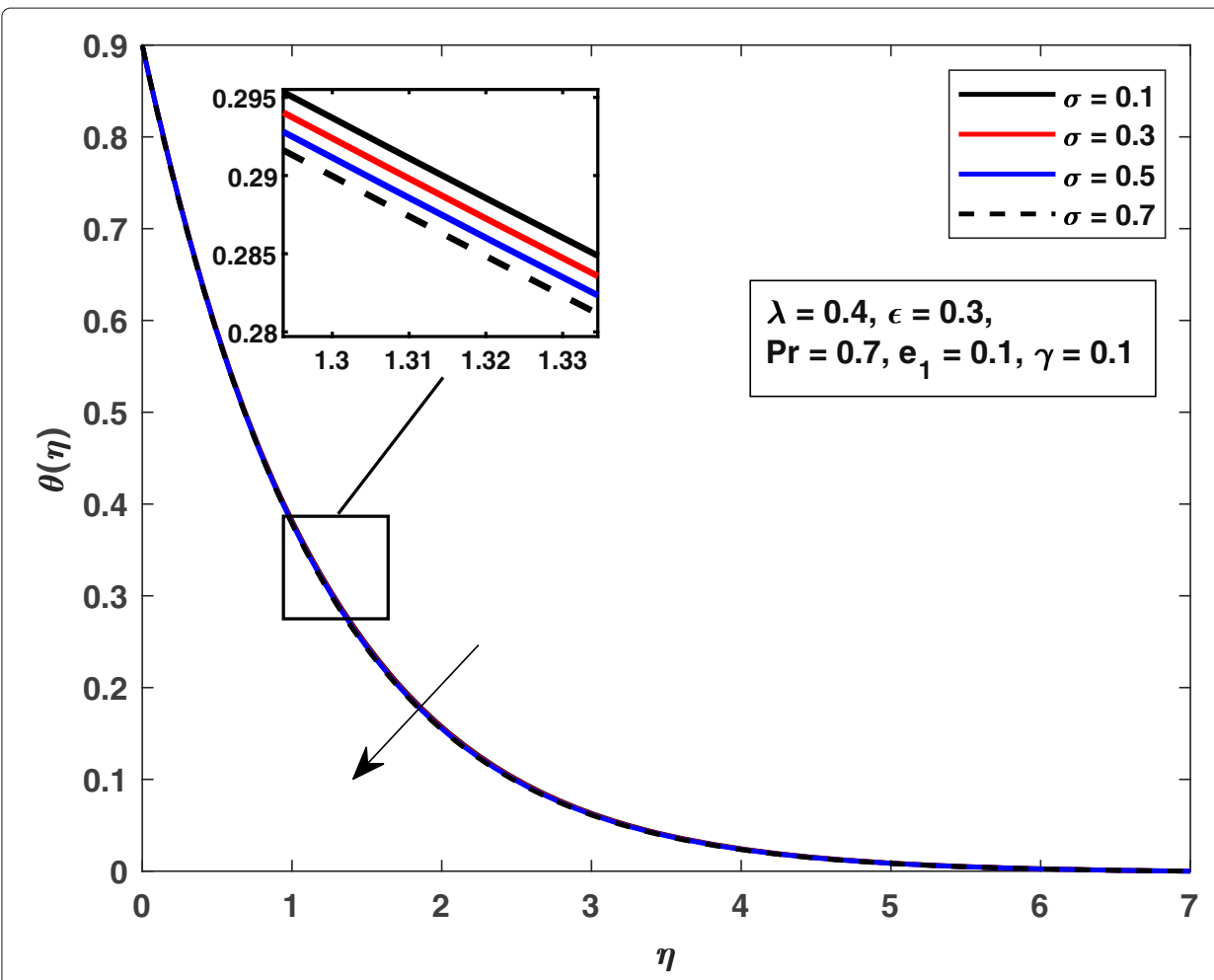

Fig. 5 Impact of the fluid parameter $\sigma$ on $\theta(\eta)$ 


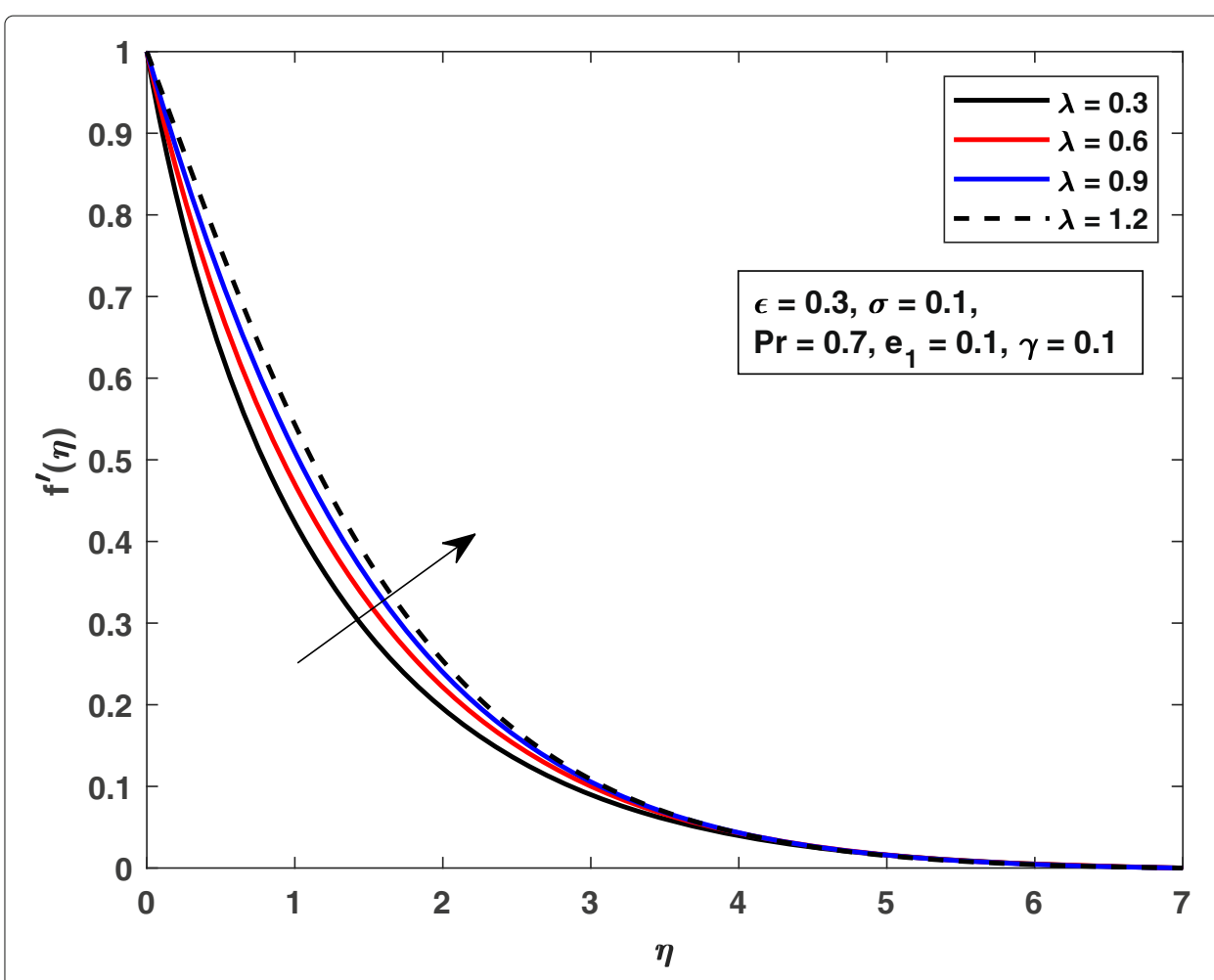

Fig. 6 Impact of the mixed convection parameter $\lambda$ on $f^{\prime}(\eta)$

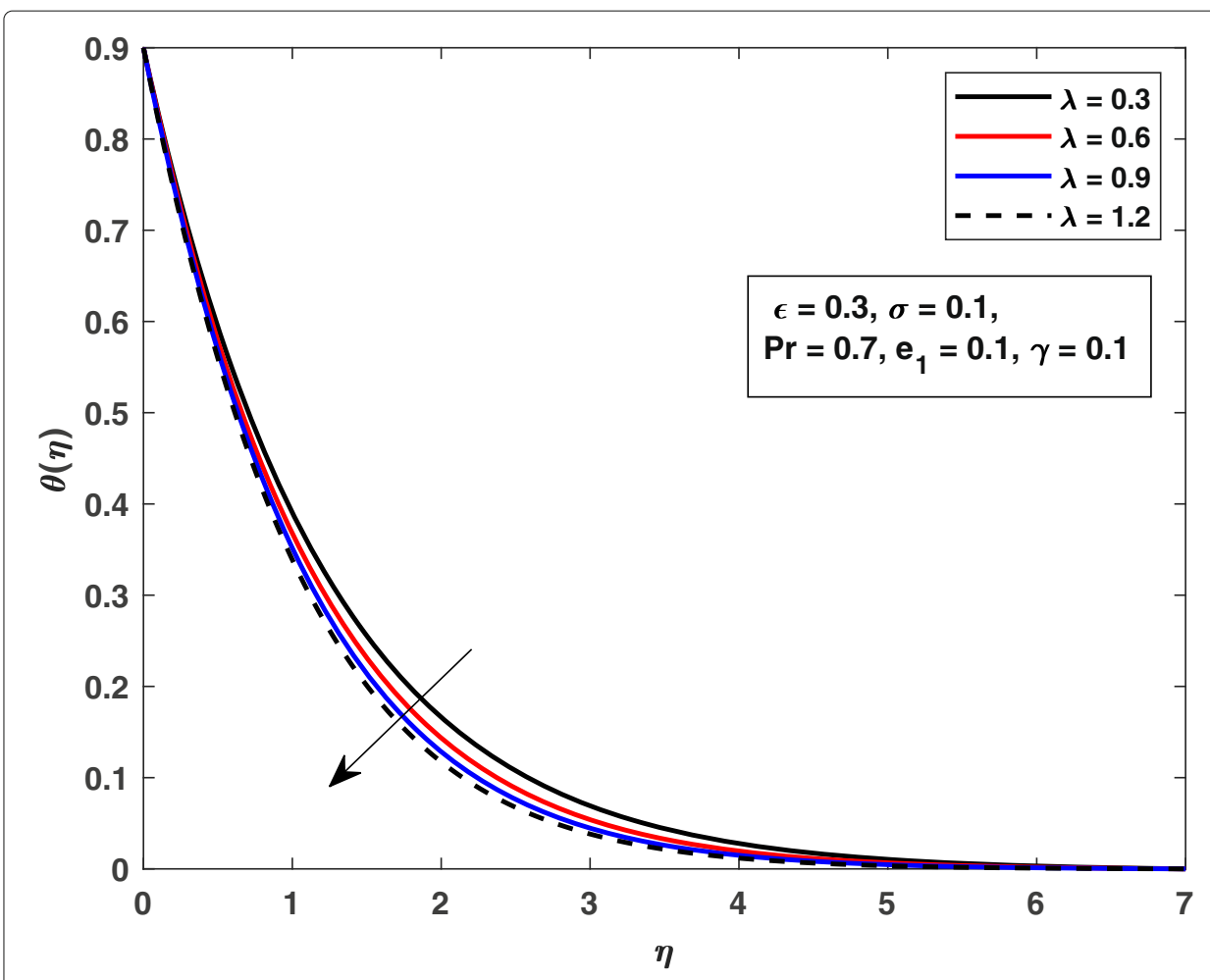

Fig. 7 Impact of the mixed convection parameter $\lambda$ on $\theta(\eta)$ 


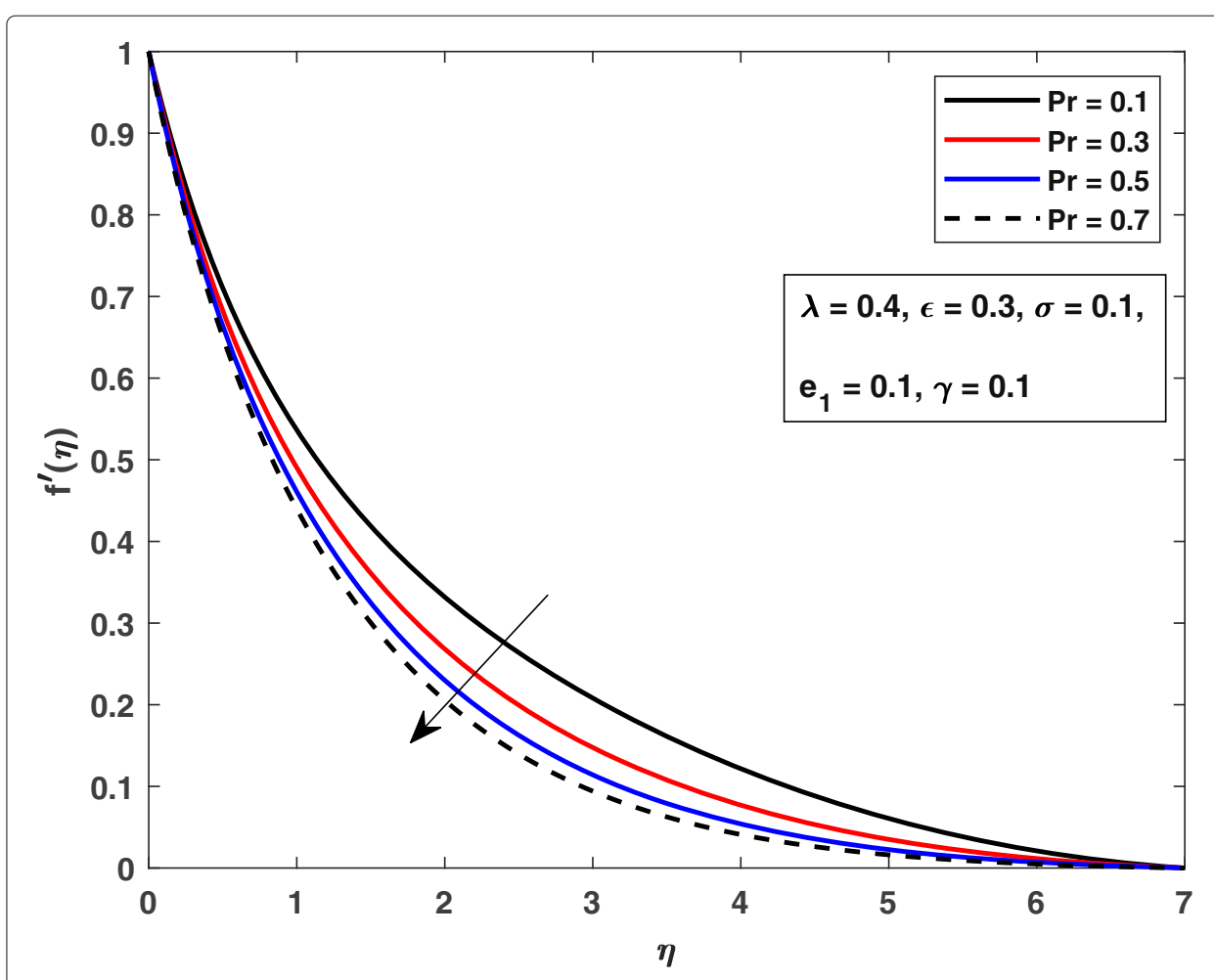

Fig. 8 Impact of the Prandtl number Pron $f^{\prime}(\eta)$

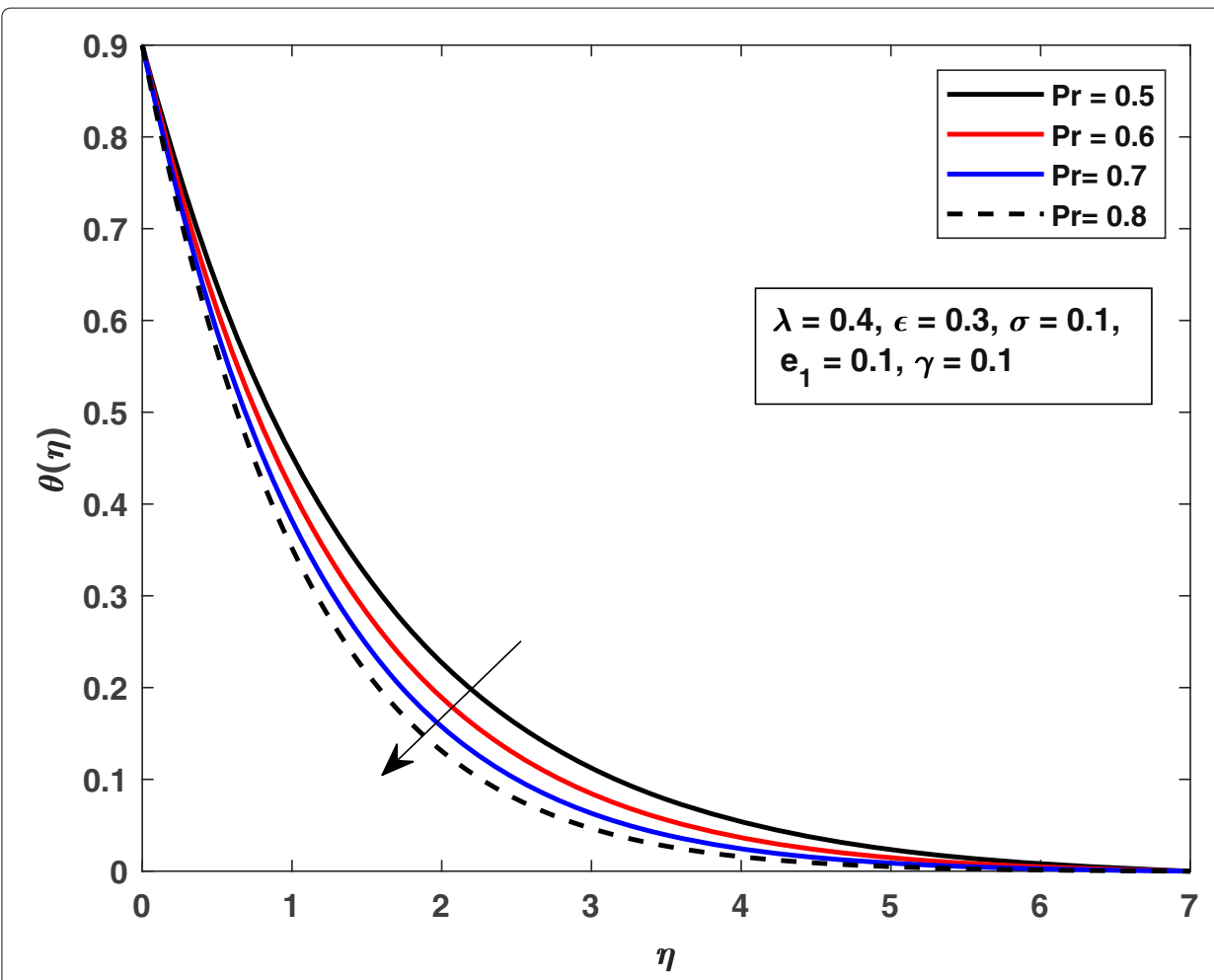

Fig. 9 Impact of the Prandt| number $\operatorname{Pr}$ on $\theta(\eta)$ 


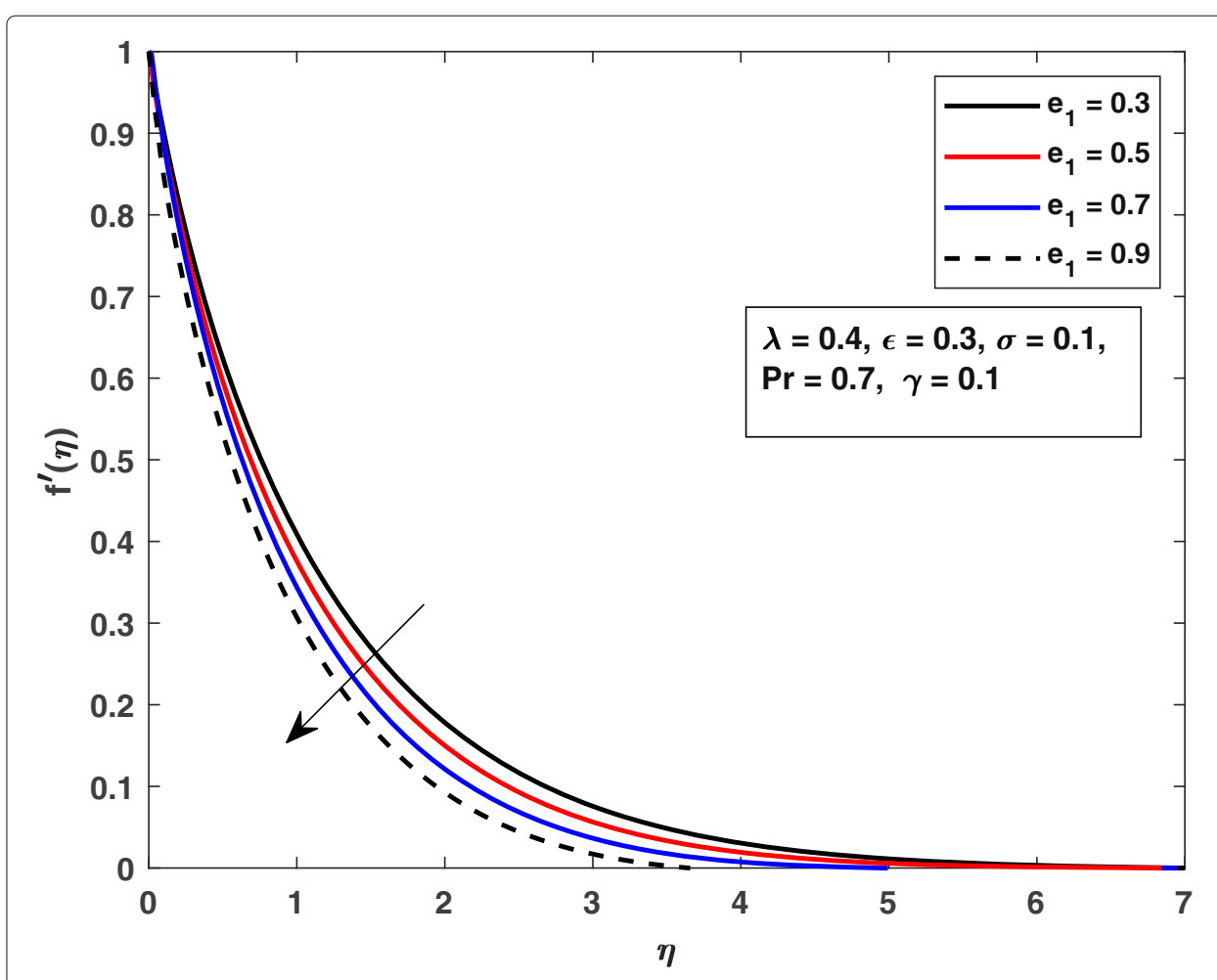

Fig. 10 Impact of the thermal stratification parameter $e_{1}$ on $f^{\prime}(\eta)$

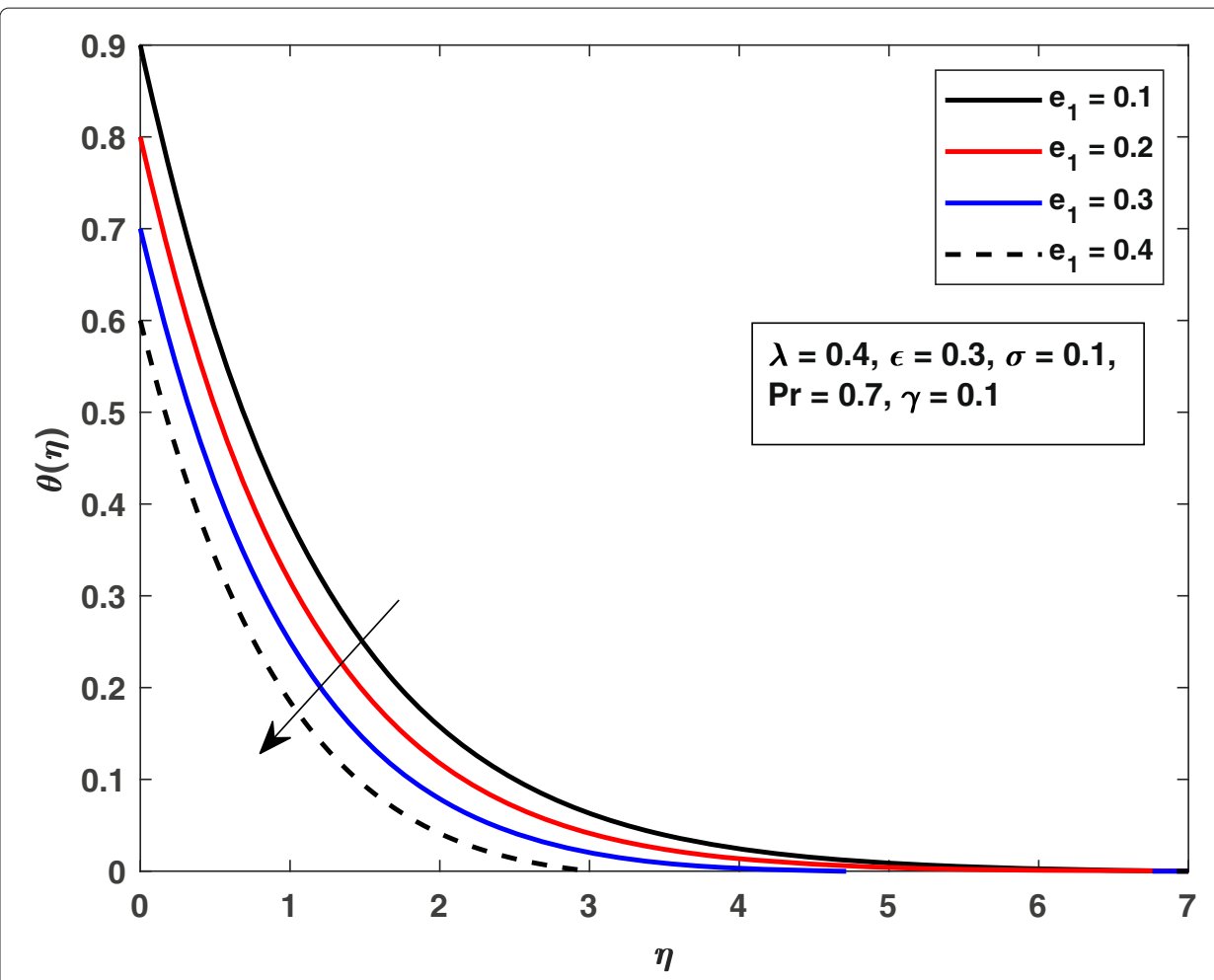

Fig. 11 Impact of the thermal stratification parameter $e_{1}$ on $\theta(\eta)$ 


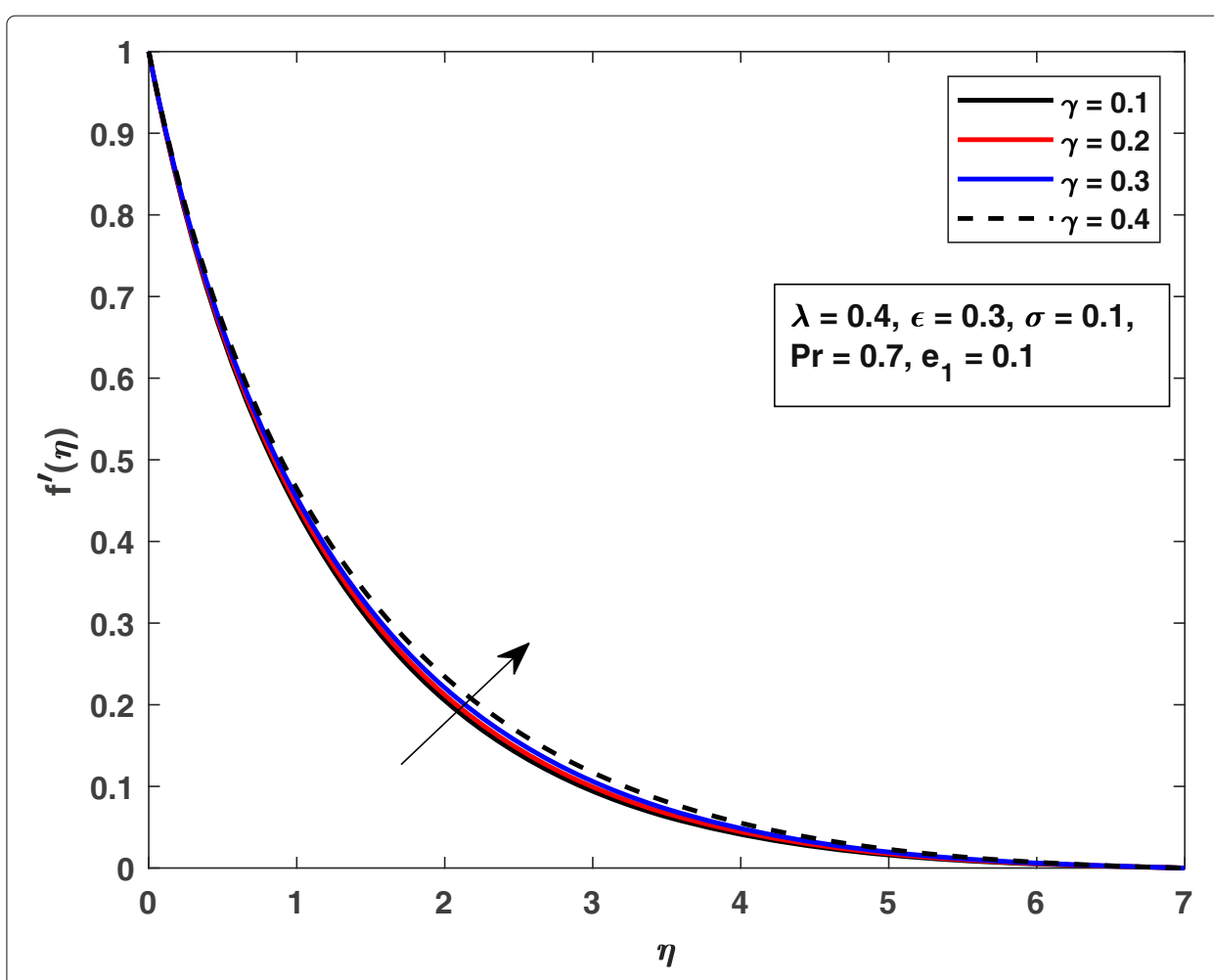

Fig. 12 Impact of the heat generation/absorption parameter $\gamma$ on $f^{\prime}(\eta)$

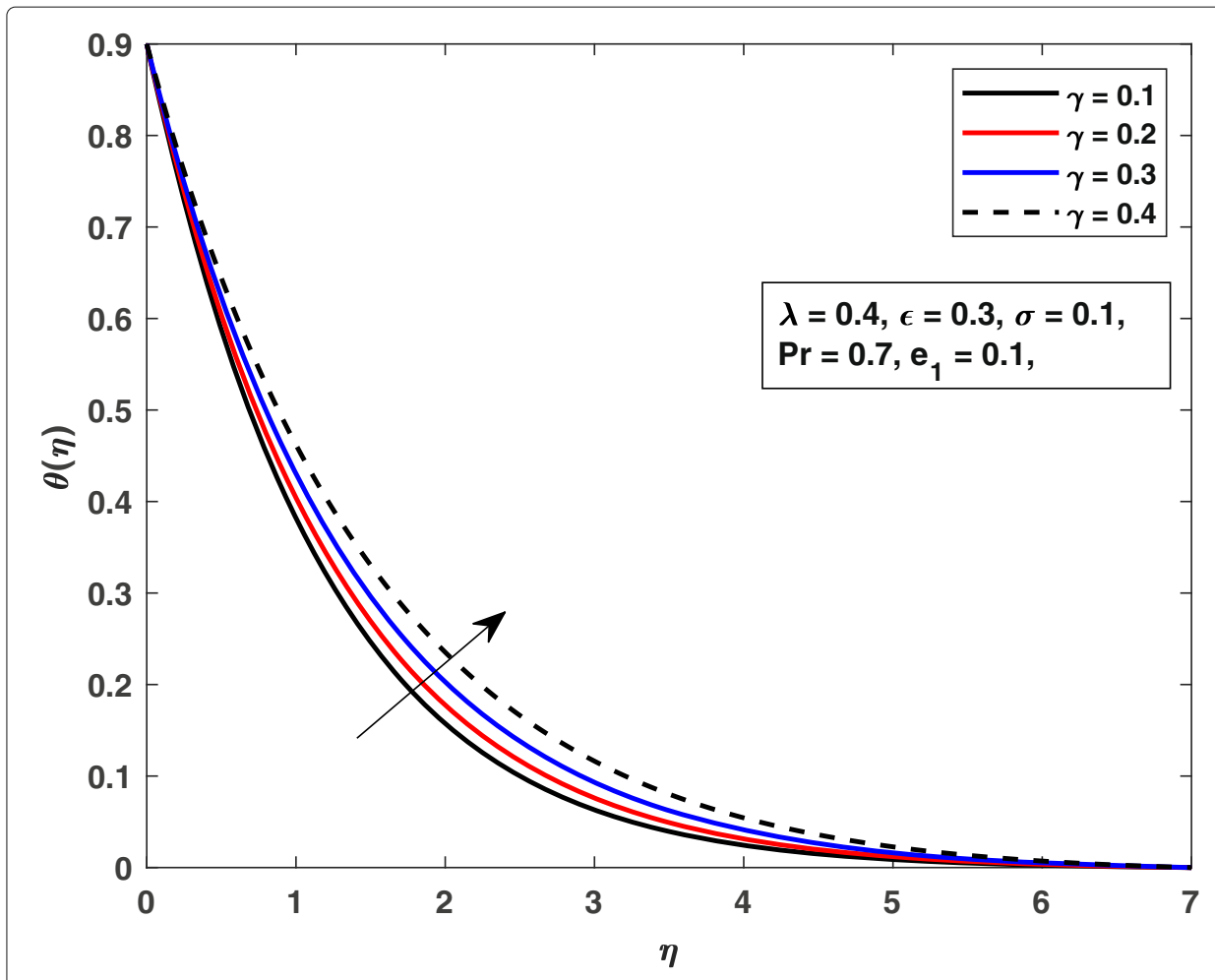

Fig. 13 Impact of the heat generation/absorption parameter $\gamma$ on $\theta(\eta)$ 
Table 1 Impact of different parameters on Skin friction coefficient and Nusselt number

\begin{tabular}{llllllll}
\hline$\epsilon$ & $\sigma$ & $\lambda$ & $\operatorname{Pr}$ & $e_{1}$ & $\gamma$ & Skin friction & Nusselt number \\
\hline 0.1 & 0.1 & 0.1 & 0.7 & 0.3 & 0.1 & -0.99532140 & -0.92008064 \\
0.3 & 0.1 & 0.1 & 0.7 & 0.3 & 0.1 & -0.92212766 & -0.94502770 \\
0.5 & 0.1 & 0.1 & 0.7 & 0.3 & 0.1 & -0.86289107 & -0.96578339 \\
0.7 & 0.1 & 0.1 & 0.7 & 0.3 & 0.1 & -0.81376433 & -0.98331652 \\
0.1 & 0.3 & 0.1 & 0.7 & 0.3 & 0.1 & -0.99879976 & -0.91964180 \\
0.1 & 0.5 & 0.1 & 0.7 & 0.3 & 0.1 & -0.99220366 & -0.91919776 \\
0.1 & 0.7 & 0.1 & 0.7 & 0.3 & 0.1 & -0.99061931 & -0.91874744 \\
0.1 & 0.1 & 0.3 & 0.7 & 0.3 & 0.1 & -0.89693700 & -0.94782060 \\
0.1 & 0.1 & 0.5 & 0.7 & 0.3 & 0.1 & -0.80448577 & -0.96950615 \\
0.1 & 0.1 & 0.7 & 0.7 & 0.3 & 0.1 & -0.71598146 & -0.98782004 \\
0.1 & 0.1 & 0.1 & 0.5 & 0.3 & 0.1 & -0.98595104 & -0.73456804 \\
0.1 & 0.1 & 0.1 & 0.3 & 0.3 & 0.1 & -0.97292060 & -0.52466598 \\
0.1 & 0.1 & 0.1 & 0.1 & 0.3 & 0.1 & -0.95453863 & -0.28163258 \\
0.1 & 0.1 & 0.1 & 0.7 & 0.5 & 0.1 & -0.99988132 & -1.02160811 \\
0.1 & 0.1 & 0.1 & 0.7 & 0.7 & 0.1 & -1.00431304 & -1.12162178 \\
0.1 & 0.1 & 0.1 & 0.7 & 0.9 & 0.1 & -1.00861355 & -1.22017849 \\
0.1 & 0.1 & 0.1 & 0.7 & 0.3 & 0.3 & -0.98928589 & -0.80412533 \\
0.1 & 0.1 & 0.1 & 0.7 & 0.3 & 0.5 & -0.97590361 & -0.62021799 \\
0.1 & 0.1 & 0.1 & 0.7 & 0.3 & 0.7 & -1.07448367 & -0.59516273 \\
\hline
\end{tabular}

form of graphs and tables. For different values of the specific physical parameters, the Nusselt number and skin friction are provided in the tabular form. From the present investigation, we can draw the following conclusions:

- Increase in Eyring-Powell fluid material parameter $\epsilon$ give rise to the velocity and temperature of fluid drops over stretching sheet.

- Increasing the Eyring-Powell material parameter $\sigma$ shows a rise in temperature but decline of velocity profile.

- When mixed convection parameter $\lambda$ is increased, the velocity of fluid increases; however, temperature falls.

- With increase in Prandtl number Pr, the velocity and temperature of fluid show reduction behavior.

- The strength of the thermal stratification parameter $e_{1}$ can help to control the velocity and temperature of fluid.

- By increasing the values of heat generation parameter $\gamma$, we get the increment in both velocity and temperature profiles.

Acknowledgements

The authors would like to thank the Editor and anonymous reviewers for their insightful comments and suggestions.

Authors' contributions

M. Bilal carried out the problem design, code validation, methodology, reading, and correction. S. Ashbar did the computation, draft preparation, and writing. The authors read and approved the final manuscript.

Funding

The authors declare that they have no funding. 


\section{Competing interests}

The authors declare that they have no competing interests.

Received: 2 May 2020 Accepted: 28 July 2020

Published online: 12 August 2020

References

1. Eldesoky, I. M., Abdelsalam, S. I., El-Askary, W. A., Ahmed, M. M.: Concurrent development of thermal energy with magnetic field on a particle-fluid suspension through a porous conduit. Bio NanoSci. 9, 186-202 (2019)

2. Abdelsalam, S. I., Bhatti, M. M.: New insight into AuNP applications in tumour treatment and cosmetics through wavy annuli at the nanoscale. Sci. Rep. 9, 260 (2019)

3. Abdelsalam, S. I., Bhatti, M. M.: The study of non-newtonian nanofluid with hall and ion slip effects on peristaltically induced motion in a non-uniform channel. RSC Adv. 8, 7904 (2018)

4. Bhatti, M. M., Marin, M., Zeeshan, A., Ellahi, R., Abdelsalam, S. I.: Swimming of motile gyrotactic microorganisms and nanoparticles in blood flow through anisotropically tapered arteries. Front. Phys. 8, 95 (2020)

5. Sohail, M., Naz, R., Abdelsalam, S. I.: Application of non-fourier double diffusions theories to the boundary-layer flow of a yield stress exhibiting fluid model. Physica A. 537, 122753 (2020)

6. Abdelsalam, S. I., Bhatti, M. M.: Anomalous reactivity of thermo-bioconvective nanofluid towards oxytactic microorganisms. Appl. Math. Mech. Engl. Ed. 41(5), 711-724 (2020)

7. Elmaboud, Y. A., Abdelsalam, S. I., Mekheimer, K., Vafai, K.: Electromagnetic flow for two-layer immiscible fluids. Engr. Sci. Tech. Int. J. 22, 237-248 (2019)

8. Mekheimera, K. S., Komyc, S. R., Abdelsalam, S. I.: Simultaneous effects of magnetic field and space porosity on compressible Maxwell fluid transport induced by a surface acoustic wave in a microchannel. Chin. Phys. B. 22(12), 124702 (2013)

9. Abdelsalamab, S. I., Vafai, K.: Combined effects of magnetic field and rheological properties on the peristaltic flow of a compressible fluid in a microfluidic channel. Eurp. J. Mech. B/Fluids. 65, 398-411 (2017)

10. Akbar, N. S., Khan, Z. H.: Effect of variable thermal conductivity and thermal radiation with CNTS suspended nanofluid over a stretching sheet with convective slip boundary conditions: Numerical study. J. Mol. Liq. 222, 279-286 (2016)

11. Rana, S., Mehmood, R., Akbar, N. S.: Mixed convective oblique flow of a casson fluid with partial slip, internal heating and homogeneous heterogeneous reactions. J. Mol. Liq. 222, 1010-1019 (2016)

12. Akbar, N. S., Tripathi, D., Khan, Z. H., Bég, O. A.: A numerical study of magnetohydrodynamic transport of nanofluids over a vertical stretching sheet with exponential temperature-dependent viscosity and buoyancy effects. Chem. Phy. Lett. 661(16), 20-30 (2016)

13. Akbar, N. S., Khan, Z. H.: Magnetic field analysis in a suspension of gyrotactic microorganisms and nanoparticles over a stretching surface. J. Magnet. Magn. Mater. 410(15), 72-80 (2016)

14. Chen, C.-H.: Laminar mixed convection adjacent to vertical, continuously stretching sheets. Heat Mass Transf. 33(5-6), 471-476 (1998)

15. Ali, M. E.: The effect of variable viscosity on mixed convection heat transfer along a vertical moving surface. Int. J. Therm. Sci. 45(1), 60-69 (2006)

16. Hayat, T., Abbas, Z., Pop, l., Asghar, S.: Effects of radiation and magnetic field on the mixed convection stagnation-point flow over a vertical stretching sheet in a porous medium. Int. J. Heat Mass Transf. 53(1-3), 466-474 (2010)

17. Ali, M., Al-Yousef, F.: Laminar mixed convection from a continuously moving vertical surface with suction or injection. Heat Mass Transf. 33(4), 301-306 (1998)

18. Khan, M., Salahuddin, T., Malik, M., Mallawi, F. O.: Change in viscosity of williamson nanofluid flow due to thermal and solutal stratification. Int. J. Heat Mass Transf. 126, 941-948 (2018)

19. Hayat, T., Qayyum, S., Imtiaz, M., Alsaedi, A.: Double stratification in flow by curved stretching sheet with thermal radiation and joule heating. J. Therm. Sci. Eng. Appl. 10(2), 021010 (2018)

20. Hayat, T., Javed, M., Imtiaz, M., Alsaedi, A.: Double stratification in the MHD flow of a nanofluid due to a rotating disk with variable thickness. Eur. Phys. J. Plus. 132(3), 146 (2017)

21. Sakiadis, B. C.: Boundary-layer behavior on continuous solid surfaces: I. boundary-layer equations for two-dimensional and axisymmetric flow. AIChE J. 7, 26-28 (1961)

22. Sakiadis, B.: Boundary-layer behavior on continuous solid surfaces: li. the boundary layer on a continuous flat surface. AiChE J. 7(2), 221-225 (1961)

23. Dandapat, B., Gupta, A.: Flow and heat transfer in a viscoelastic fluid over a stretching sheet. Int. J. Non-Linear Mech. 24(3), 215-219 (1989)

24. Erickson, L., Fan, L., Fox, V.: Heat and mass transfer on moving continuous flat plate with suction or injection. Ind. Eng. Chem. Fundam. 5(1), 19-25 (1966)

25. Crane, L. J.: Flow past a stretching plate. Z. Angew. Math. Phys. 21(4), 645-647 (1970)

26. Andersson, H. I., Bech, K. H., Dandapat, B. S.: Magnetohydrodynamic flow of a power-law fluid over a stretching sheet. Int. J. Non-Linear Mech. 27(6), 929-936 (1992)

27. Hayat, T., Muhammad, T., Shehzad, S. A., Alsaedi, A.: Ananalytical solution for magneto-hydrodynamic oldroyd-b nanofluid flow induced by a stretching sheet with heatgeneration / absorption. Int. J. Therm. Sci. 111, 274-288 (2017)

28. Sajid, M., Ali, N., Abbas, T. J. Z.: Stretching a curved surface in a viscous fluid. Chin. Phys. Lett. 27, 024703 (2010)

29. Ibrahim, W., Hindebu, B.: Magnetohydrodynamic (mhd) boundary layer flow of Eyring-Powell nanofluid past stretching cylinder with cattaneo-christov heat flux model. Nonlinear Eng. 8(1), 303-317 (2019)

30. Eldabe, N., Hassan, A., Mohamed, M. A.: Effect of couple stresses on the MHD of a non-Newtonian unsteady flow between two parallel porous plates. Z Naturforsch. A. 58(4), 204-210 (2003)

31. Malik, M., Khan, I., Hussain, A., Salahuddin, T.: Mixed convection flow of MHD Eyring-Powell nanofluid over a stretching sheet: A numerical study, Vol. 5 (2015) 
32. Ogunseye, H. A., Sibanda, P.: A mathematical model for entropy generation in a Powell-Eyring nanofluid flow in a porous channel. Heliyon. 5(5), e01662 (2019)

33. Parand, Moayeri, L.D.: A numerical investigation of the boundary layer flow of an Eyring-Powell fluid over a stretching sheet via rational chebyshev functions. Eur. Phys. J. Plus Vol. 132, 325 (2017)

34. Salleh, M. Z., N, R., I, P.: Boundary layer flow and heat transfer over a stretching sheet with Newtonian heating. J. Taiwan Inst. Chem. Eng. 41(6), 651-655 (2010)

35. Ramzan, M., Bilal, M., Kanwal, S., Chung, J. D.: Effects of variable thermal conductivity and non-linear thermal radiation past an eyring powell nanofluid flow with chemical reaction. Commun. Theor. Phys. 67, 723-731 (2017)

36. Ramzan, M., Bilal, M., Chung, J. D.: Radiative Williamson nanofluid flow over a convectively heated Riga plate with chemical reaction - a numerical approach. Chin. J. Phys. 55, 1663-1673 (2017)

37. Bilal, M., Sagheer, M., Hussain, S.: On MHD 3D upper convected Maxwell fluid flow with thermophoretic effect using non-linear radiative heat flux. Can. J. Phys. 96, 1-10 (2018)

38. Sagheer, M., Bilal, M., Hussain, S., Ahmed, R. N.: Thermally radiative rotating magneto-nanofluid flow over an exponential sheet with heat generation and viscous dissipation: A comparative study. Commun. Theor. Phys. 69 317-328 (2018)

39. Bilal, M., Sagheer, M., Hussain, S.: Numerical study of magnetohydrodynamics and thermal radiation on Williamson nanofluid flow over a stretching cylinder with variable thermal conductivity. Alex. Eng. J. 57, 3281-3289 (2018)

40. Bilal, M.: Micropolar flow of EMHD nanofluid with nonlinear thermal radiation and slip effects. Alex. Eng. J. 59, 965-976 (2020)

\section{Publisher's Note}

Springer Nature remains neutral with regard to jurisdictional claims in published maps and institutional affiliations.

\section{Submit your manuscript to a SpringerOpen ${ }^{\circ}$} journal and benefit from:

- Convenient online submission

Rigorous peer review

- Open access: articles freely available online

- High visibility within the field

- Retaining the copyright to your article

Submit your next manuscript at $\gg$ springeropen.com 